\title{
Per Rectal Bleeding in Children: Experiences in the Department of Paediatric Surgery in BSMMU
}

\author{
Alam S, Islam KMD, Mohammad N, Nooruzzaman M \\ Bangabandhu Sheikh Mujib Medical University, Dhaka, Bangladesh \\ e-mail: shohelims@yahoo.co.in
}

\begin{abstract}
Per rectal bleeding is a frequently encountered clinical complaint in routine medical/surgical practice in paediatric patients. It has different aetiology in both extremes of age. This study was carried out in an attempt to find out causes, presentation and the proper management that can be offered to the affected infants and children.This retrospective study was carried out from January 2012 to December 2014 in the department of Paediatric Surgery of Bangabandhu Sheikh Mujib Medical University (BSMMU), Dhaka, Bangladesh. All patients presenting with the complaint of per rectal bleeding were included. But patients who needed emergency surgical intervention were excluded from this study. The data were reviewed for gender, age, causes of rectal bleeding and type, number, site, recurrence rate and the modality of treatment employed in children having colorectal polyp. Technetium-labeled red blood cells scans was used for the diagnosis of Meckel's Diverticulum. Complete blood picture and routine stool examination were done for all cases.Most polyp cases were diagnosed with digital rectal examination (DRE). Colonoscopy was performed for some cases in the Paediatric Gastroenterology Department of BSMMU. Also all the rectal polyps and colonic mucosal biopsies taken during colonoscopy submitted to histopathological examination. Per rectal bleeding was the chief complaint in $326(1.5 \%)$ patients Out of 21,533 patients presenting to the outpatient department of Paediatric Surgery of BSMMU, Dhaka, Bangladesh over a period of three years. In this study, it was reviewed 326 patients, among them $208(63.89 \%)$ were boys and 118 (36.19\%) were girls. The male female ratio was 1.8:1. The ages ranged from 14 months to 14 years (mean age: 5.8years) at diagnosis. The most common aetiology was juvenile polyps which were found in $209(64.11 \%)$ of the cases. It was to be found that anal fissure in $33(10.12 \%)$ patients, rectal prolapse in $27(8.2 \%)$ patients, non-specific colitis in 15 $(4.60 \%)$ patients, Meckel's Diverticulitis in $3(0.9 \%)$ patients, juvenile polyposis coli in $5(1.5 \%)$ patients and familial adenomatous polyposis coli (FAP) in $4(1.2 \%)$ patients. However, the cause of per rectal bleeding remained unknown suspecting chronic constipation in $30(9.20 \%)$ patients. No statistically significant differences were observed between males and females as well as different age groups regarding the means of the underlying causes of per rectal bleeding in children $(p>$ 0.05 ). The prevalence of anal fissure in less than 2 years old patients and juvenile polyps in the 2-6 years old patients were significantly higher than the other causes $(p<0.001)$. Other causes of per rectal bleeding prevailed in children were more than 2 years old. Colorectal polyps are common causes of per rectal bleeding in children. Proper physical examination including DRE along with the colonoscopy promotes both rapid and accurate diagnosis and the opportunity for immediate therapeutic measures.
\end{abstract}

Keywords: Per rectal bleeding, Rectal polyp, DRE, Colonoscopy

\section{Introduction}

Per rectal bleeding is a major clinical problem in our medical and surgical practice in paediatric
patients.Per rectal bleeding alone accounted for $0.3 \%$ of the chief complaints in more than 40,000 
patients present to a major urban emergency department. ${ }^{1}$ Another study suggested that there were 23,383 paediatric discharges with the diagnosis of gastrointestinal bleeding account for $0.5 \%$ of all discharges. The highest incidence of gastrointestinal bleeding was attributable to cases coded as blood in stool (17.6 per 10,000 discharges). ${ }^{2}$ Most of the general practitioners do not have much appreciation regarding the aetiologies and management modalities of per rectal bleeding in paediatric age group. This may explain the mismanagement of this problem. Per rectal bleeding in infants and children is commonly encountered in clinical practice, although its epidemiology has not been well evaluated. ${ }^{3.4}$ The aetiology of per rectal bleeding in children is different from that in adults. The causes are usually simple and need little or no treatment e.g. anal fissure, juvenile polyps but sometimes it may present as more serious and threatening conditions e.g. intussusception, midgut volvulus, Meckel's diverticulum and peptic ulcer disease. ${ }^{4,5}$ Chronic cases of minor per rectal bleeding produces significant anemia. Accordingly, detection and localization of the aetiology is an important part in the management of these children. A carefully taken history, proper and complete examination of the perianal region, DRE and routine stool examination can find out the most common causes of per rectal bleeding among paediatric patients. ${ }^{4,5}$ More advanced diagnostic techniques e.g. endoscopy, radiology, technetium-labeled red blood cells scans and angiography are used for the diagnosis of more difficult cases.

\section{Materials and Methods}

In this study, it was reviewed 326 children with per rectal bleeding from January 2012 to December 2014, who were managed in the Paediatric Surgery Department of BSMMU, Dhaka, Bangladesh.

All patients presented with per rectal bleeding for variable period, ranging from seven days to two years. Along with per rectal bleeding some also complaints of something coming out per rectally during defecation which spontaneously go within the anal canal, some complain of pain during defecation, some complain of occasional diarrhea or constipation. It was excluded those who needed emergency surgical intervention as there is no facilities for emergency operations in
Paediatric Surgery Department of BSMMU. Proper history was taken and all patients were clinically examined including DRE. Complete blood picture and routine stool examination done for all the case.

In case of rectal polyp, polypectomy was done under general anaesthesia as a day case procedure and the polyp was sent for histopathology.

In cases where no polyps were detected using DRE, empirical management provided with the provisional diagnosis of suspected infectious colitis secondary to Gram- negative bacteria and/or entamoeba histolytica. The treatment regime offered consisted of metronidazole combined with or without nalidixic acid for a period of 7 to 14 days. Results of routine stool examination were recorded and assessed. In cases treated on empirical basis and still continue to have persistent per rectal bleeding, colonoscopy was undertaken.

For juvenile polyposis coli, most of the polyps found in rectum and sigmoid colon, so subtotal colectomy with or without colostomy or ileostomy was performed initially. For recurrence, two patients required pancolectomy with ileoanal anastomosis with covering proximal ileostomy. For FAP pancolectomy with ileoanal anastomosis with covering proximal ileostomy were performed.

All these operations done under general anaesthesia after admitting these patients in our department. Proper family history were taken. Colonoscopy were performed of those patients suffering from Juvenile polyposis coli and FAP and proper counseling were done before operation.

These patients were followed-up in the outpatient department in follow-up protocol. Three $(0.9 \%)$ patients were submitted to explorative laparotomy that showed a broad base bleeding Meckel's diverticulum for which a wedge resection with a primary closure was undertaken.

The study detected 33 cases of anal fissure which were managed successfully by giving stool softener and rectal ointment. Child with rectal prolapse first treated with changes of dietary habit along with stool softener. Most of the child improved by medical treatment. Only $5(18.5 \%)$ child required Thiersch's procedure. 
All the patients were categorized into four age groups of less than 2, 2-6, 6-10, and 10-14 years old. Age, sex, causes of rectal bleeding and type, number, site, recurrence rate and the modality of treatment employed in children having colorectal polyp were collected and analyzed.

Data were analysed using the SPSS software (version12.0). Statistical differences between the parameters were tested using Chi-square test. The results were expressed as mean $\pm \mathrm{SD}$ and proportions as appropriate

\section{Results}

Per rectal bleeding was identified as the chief complaint in $326(1.5 \%)$ patients out of 21,533 patients presented to the out-patient department of Paediatric Surgery of BSMMU, Dhaka, Bangladesh over a three year period

In this study, it was reviewed 326 patients, among them 208 (63.89\%) were boys and 118 (36.19\%) were girls. The male: female ratio was 1.8:1. The ages ranged from 14 months to 14 years (Mean \pm SD- $5.81 \pm 3.02$ ) at diagnosis. (table I).

Table I: Demographic profile of the per rectal bleeding in children $(n=326)$

\begin{tabular}{|c|c|c|}
\hline Age (years) & Frequency & Percentage (\%) \\
\hline$<2$ & 55 & 16.9 \\
\hline $2-6$ & 180 & 55.2 \\
\hline $6-10$ & 58 & 17.8 \\
\hline $10-14$ & 33 & 10.1 \\
\hline Mean \pm SD & \multicolumn{2}{|c|}{$5.81 \pm 3.02(15$ months -14 years $)$} \\
\hline Sex & & \\
\hline Male & 208 & 63.8 \\
\hline Female & 118 & 36.2 \\
\hline
\end{tabular}

The most common aetiology was Juvenile polyps which were found in $209(64.11 \%)$ of the cases. Anal fissure was diagnosed in $33(10.12 \%)$ patients, rectal prolapse in $27(8.2 \%)$ patients, non-specific colitis in $15(4.60 \%)$ patients, Meckel's Diverticulitis in $3(0.9 \%)$ patients, Juvenile polyposis coli in $5(1.5 \%)$ patients and FAP in $4(1.2 \%)$ patients. However, the cause of per rectal bleeding remained unknown suspecting chronic constipation in $30(9.20 \%)$ patients.No statistically significant differences were observed between males and females as well as different age groups regarding the means of the underlying causes of per rectal bleeding in children $(p>0.05)$. (table II)
Table II: Aetiology of the per rectal bleeding in children $(\mathrm{n}=326)$

\begin{tabular}{lcccc}
\hline Aetiology & Total & $\begin{array}{c}\text { Male } \\
(\mathbf{n = 2 0 8})\end{array}$ & $\begin{array}{c}\text { Female } \\
(\mathbf{n = 1 1 8})\end{array}$ & $\begin{array}{c}p- \\
\text { value }\end{array}$ \\
\hline $\begin{array}{l}\text { Juvenile polyp } \\
\text { Anal fissure }\end{array}$ & 209 & $134(64.1)$ & $75(35.9)$ & 0.876 \\
$\begin{array}{l}\text { Rectal prolapse } \\
\text { Non-specific colitis }\end{array}$ & 27 & $21(63.6)$ & $12(36.4)$ & 0.983 \\
$\begin{array}{l}\text { Juvenile poliposis } \\
\text { coli }\end{array}$ & 15 & $9(60.0)$ & $9(33.3)$ & 0.747 \\
$\begin{array}{l}\text { Familial } \\
\text { adenomatous } \\
\text { polyposis coli }\end{array}$ & 5 & $3(60.0)$ & $2(40.0)$ & 0.858 \\
$\begin{array}{l}\text { Meckel's } \\
\text { diverticulitis }\end{array}$ & 3 & $3(75.0)$ & $1(25.0)$ & 0.639 \\
$\begin{array}{l}\text { Unknown cause } \\
\text { suspecting chronic } \\
\text { constipation }\end{array}$ & 30 & $18(60.0)$ & $12(40.0)$ & 0.649 \\
\begin{tabular}{l} 
Total \\
\hline
\end{tabular} & 326 & $208(63.8)$ & $118(36.2)$ & \\
\hline
\end{tabular}

The prevalence of anal fissure in less than 2 years old patients and juvenile polyps in the 2-6 years old patients were significantly higher than the other causes $(p<0.001)$. Other causes of per rectal bleeding prevailed in children were more than 2 years old ( table 3 ).

Table III: Per rectal bleeding in children in different age group $(\mathrm{n}=326)$

\begin{tabular}{lccccc}
\hline \multirow{2}{*}{ Aetiology } & \multicolumn{5}{c}{ Age (years) } \\
& $25(12.0)$ & $143(68.4)$ & $30(14.4)$ & $11(5.3)$ & $<0.001^{\mathrm{s}}$ \\
\hline Juvenile polyp & $20(60.6)$ & $7(21.2)$ & $4(12.1)$ & $2(6.1)$ & $<0.001^{\mathrm{s}}$ \\
Anal fissure & $4(14.8)$ & $10(37.0)$ & $7(25.9)$ & $6(22.2)$ & 0.060 \\
Rectal prolapse & $1(6.7)$ & $5(33.3)$ & $3(20.0)$ & $6(40.0)$ & $0.001^{\mathrm{s}}$ \\
$\begin{array}{l}\text { Non-specific colitis } \\
\text { Juvenile } \\
\text { polyposis coli }\end{array}$ & $0(0.0)$ & $0(0.0)$ & $3(60.0)$ & $2(40.0)$ & $0.004^{\mathrm{s}}$ \\
$\begin{array}{l}\text { Familial } \\
\text { adenomatous } \\
\text { polyposis coli }\end{array}$ & $0(0.0)$ & $2(50.0)$ & $1(25.0)$ & $1(25.0)$ & 0.635 \\
$\begin{array}{l}\text { Meckel's } \\
\text { diverticulitis }\end{array}$ & $0(0.0)$ & $2(66.7)$ & $1(33.3)$ & $0(0.0)$ & 0.729 \\
$\begin{array}{l}\text { Unknown cause } \\
\text { suspecting chronic }\end{array}$ & $5(16.7)$ & $11(36.7)$ & $9(30.0)$ & $5(16.7)$ & 0.101 \\
$\begin{array}{l}\text { constipation } \\
\text { Total }\end{array}$ & & & & & \\
\hline
\end{tabular}

Polyps were diagnosed by DRE in 188(86.24\%) patients and by colonoscopic examination in 30 $(13.76 \%)$ patients. A single polyp was present in $168(77.06 \%)$ patients, whereas two or more than two were present in $50(22.94 \%)$ patients. In 192 $(88.07 \%)$ patient's polyps were located in the rectum, $17(7.80 \%)$ patients in the sigmoid colon, 5(2.29\%) patients in both rectum and sigmoid colon, $3(1.38 \%)$ patients in the rectum, sigmoid and transverse colon and $1(0.46 \%)$ patients in the rectum, sigmoid and ascending colon.Surgical polypectomy was performed in $188(86.24 \%)$ patients. Successful colonoscopic removal was accomplished in 21 (9.63\%) patients among the 30, diagnosed by colonoscopy. Initially subtotal colectomy with or without colostomy or ileostomy was done in five 
patients with Juvenile polyposis coli. But due to recurrence two patients underwent pancolectomy with ileoanal anastomosis with covering proximal ileostomy. It was performed pancolectomy with ileoanal anastomosis with covering proximal ileostomy in four patients having FAP. Recurrence was observed in $13(6.22 \%)$ patients with juvenile polyp, in two (40\%) patients in juvenile polyposis coli. (table IV)

Table IV: Colorectal polyp- in 218 children

\begin{tabular}{|c|c|c|c|}
\hline Particulars & & Frequency & $\begin{array}{c}\text { Percentage } \\
(\%)\end{array}$ \\
\hline \multirow[t]{3}{*}{ Type } & Juvenile Polyp & 209 & 95.87 \\
\hline & Juvenile Polyposis Coli & 5 & 2.29 \\
\hline & Familial Adenomatous Polyposis Coli (FAP) & 4 & 1.84 \\
\hline \multirow[t]{5}{*}{ Site } & Rectum & 192 & 88.07 \\
\hline & Sigmoid Colon & 17 & 7.80 \\
\hline & Rectum and Sigmoid Colon & 5 & 2.29 \\
\hline & Rectum, Sigmoid Colon and Transverse Colon & 3 & 1.38 \\
\hline & Rectum, Sigmoid Colon and Ascending Colon & 1 & 0.46 \\
\hline \multirow[t]{2}{*}{ Number } & Single & 168 & 77.06 \\
\hline & More than one & 50 & 22.94 \\
\hline Detection & Digital per rectal & 188 & 86.24 \\
\hline of polyp & Colonoscopy & 30 & 13.76 \\
\hline Procedure & Surgical polypectomy & 188 & 86.24 \\
\hline \multirow[t]{3}{*}{ of removal } & Colonoscopically & 21 & 9.63 \\
\hline & Subtotal Colectomy with or without colostomyor ileostomy & 3 & 1.38 \\
\hline & Pancolectomy with ileoanal anaestomosis with covering proximal ileostomy & 6 & 2.75 \\
\hline \multirow[t]{2}{*}{ Recurrence } & Juvenile Polyp & 13 & 6.22 \\
\hline & Juvenile Polyposis Coli & 02 & 40 \\
\hline
\end{tabular}

It could not be performed full colonoscopic evaluation in all patients with multiple polyps in this series.

\section{Discussion}

The presence of per rectal bleeding is a major health problem in children. Per rectal bleeding alone accounted for $0.3 \%$ of the chief complaints in more than 40,000 patients present to a major urban emergency department. ${ }^{1}$ Another study suggested that there were 23,383 paediatric discharges with the diagnosis of gastrointestinal bleeding account for $0.5 \%$ of all discharges. The highest incidence of gastrointestinal bleeding was attributable to cases coded as blood in stool (17.6 per 10,000 discharges). ${ }^{2}$ It can cause stress and panic for parents, babysitters, and even physicians. Previous studies have demonstrated that per rectal bleeding in most infants and children is a benign and self-limiting condition usually requiring no treatment or one that can be managed by supportive care. ${ }^{7-9}$ The fact that a aetiologies of pediatric per rectal bleeding vary among different geographical regions and ethnic groups necessitate the investigation of the epidemiology and characteristics of this disorder in each region.
In one of the largest studies, per rectal bleeding was the chief complaint in $0.3 \%$ of more than 40,000 patients attending to Texas Children's Emergency Department between July 2009 to June $2010 .{ }^{1}$ Whereas in this study, rectal bleeding was identified as the chief complaint in 326 (1.5\%) patients out of 21,533 patients presented to the outpatient department of Paediatric Surgery of BSMMU, Dhaka, Bangladesh over a three years period.

In this study, the causes of rectal bleeding were juvenile polyps, anal fissure, rectal prolapse, non-specidfic colitis, meckel's diverticulitis, juvenile polyposis coli, FAP and unknown causes suspecting chronic constipation. The aetiologies of per rectal bleeding in our series varied significantly with previous per rectal bleeding reports. ${ }^{7,8,10,11}$ Most previous reports have shown that constipation with fissure formation was the most common cause for per rectal bleeding in toddlers and school-age children. . $^{7,11}$ Hillemeier and coworkers demonstrated that anal fissure and infectious diarrhea were the most common causes of per rectal bleeding in neonates, toddlers and schoolage children. ${ }^{9}$ In this study, anal fissure was significantly high below the two years old child. 
A study in 80 children who were managed with per rectal bleeding from January 2005 to December 2007 in various hospitals in Karachi has shown the most common causes of rectal bleeding were rectal polyps, infectious colitis, ulcerative colitis and non-specific colitis. ${ }^{12}$ Among Egyptian children, the most common cause of per rectal bleeding was infectious enterocolitis. Colorectal polyps and chronic colitis were the next common causes of per rectal bleeding respectively. ${ }^{13}$

A systematic analysis of Chinese literature found an additional 160 studies that provided relevant data in 53,951 patients showed that the three most common etiologies for per rectal bleeding in children were colorectal polyps (49\%), chronic colitis (11\%), and intussusception (9\%). Colorectal cancer was extremely rare in children. One patient with colorectal cancer was diagnosed. ${ }^{14}$

The reported prevalence of juvenile rectal polyps in children undergoing endoscopic assessment for different indications ranges from $4 \%$ to $17 \%$ in Western literature. ${ }^{12,14,15}$ In India it ranked to $61 \%$ reflecting the high incidence in this area. ${ }^{16}$ In the current study only $30(13.76 \%)$ patients required colonoscopic examination.

Rectal polyps can be a cause of chronic anemia secondary to passive and persistent blood loss in the stool. ${ }^{17,18}$ But no such anaemia were noticed in this study.

Polyps were diagnosed in $188(86.24 \%)$ patients in our study by DRE, which is still an important tool in diagnosis. Other studies reported $60-70 \%$ of rectal polyps are diagnosed by DRE. ${ }^{19}$ Juvenile rectal polyps in children are usually benign, nevertheless, adenomatous changes and cases of colorectal carcinomas had been reported to arise from juvenile rectal polyps. ${ }^{20,21}$ In this study, report of any single case with dysplastic changes, however, other workers had reported this change in from $0.5 \%-11 \%$ in their series. ${ }^{17,22,23}$ Thus, all juvenile rectal polyps must be excised to avoid the potential risk of future malignancy even if they are asymptomatic.

Bai and his colleagues found that the proportion of colorectal polyp induced LGIB increased with the patients' age. ${ }^{24}$ In this study, the prevalence of colorectal polyp in the 2-6 years old group was higher in comparison to the other groups.
Good surgical technique is very important to avoid any complication. No complication was encountered fortunately in this series, however others showed 5-14\% complications like bleeding and perforation. ${ }^{23,25,26}$

Ojuawo and colleagues reported that diarrhea, vomiting, abdominal pain, anorexia, and failure to thrive were the most common accompanying symptoms of per rectal bleeding. ${ }^{27}$ In another case-control study, Arvola and coworkers reported that loose and mucous stools, abdominal pain, and vomiting were frequently detected in those children with per rectal bleeding. ${ }^{8}$

In this study, loose stool, constipation, something coming out per rectally during defecation which spontaneously go within the anal canal and in some cases pain during defecation were the most common symptoms that accompanied bleeding per rectum.

In this study recurrence was observed in $6.22 \%$ of patients with juvenile polyp. Poddar and colleagues showed in their study that recurrence rate of solitary juvenile polyp was $4.5 \%$ and $17-37.5 \%$ in patients with more than five polyps. ${ }^{28}$

This study had some limitations. First, it was a study that included all children who referred to the tertiary center with per rectal bleeding. Future studies should be population-based in order to avoid this type of bias.

Second, cases were excluded those who needed immediate surgical intervention. Thus there is no data available on patients who had per rectal bleeding secondary to surgical impressions including intussusception, volvulus, necrotizing enterocolitis, and toxic megacolon.

\section{Conclusion}

Colorectal polyps are common cause of per rectal bleeding in children in BSMMU. Proper history and physical examination including DRE along with the colonoscopic examination promotes both rapid and accurate diagnosis and the opportunity for immediate therapeutic polypectomy.

\section{References}

1. Fleischer RG, Donald HS. Rectal bleeding in the Paediatric Emergency Department. Am J Paed Emerg. 1999; 77: 1053-58. 
2. Chaitanya P, Senthil KS, Abhishek D, Mojtaba O, Michael PA, Thomas JS. Gastrointestinal bleeding in hospitalized children in th United States. Current Medical Research and Opinion. 2014; 6: 1065-69

3. Roberts ZD, Shawritz KF, Chandra KA, Harley SW, Rayhon CD, Smith $\mathrm{J}$ et al. Lower gastrointestinal bleeding in the tropics. Trop Gastroenterol. 2007; 80: 90-93.

4. Harley SW, Raybon CD, Smith AJ. Endoscopic findings in neonatal bleeding per rectum. Eup J Paed Nutr. 2008; 33: $57-63$.

5. Nilson VC, Siebert JF, Wang YT, Claxton RC, Jain S, Ritchey RM et al. Causes of bleeding per rectum in paediatric age. Am J Paed. 2008; 97:170-75.

6. Domizo VR, Chan KJ, Nicole PT. Endoscopic evaluation of bleeding per rectum in Chidren. Jap J Paed Surg. 2009; 49:735-39.

7. Fox VL. Gastrointestinal bleeding in infancy and childhood. Gastroenterol Clin North Am. 2000;29:37-66

8. Arvola T, Ruuska T, Keränen J, Hyöty H, Salminen S, Isolauri E. Rectal bleeding in infancy: clinical, allergological, and microbiological examination. Pediatrics. 2006;117:760-68.

9. Hillemeier C, Gryboski JD. Gastrointestinal bleeding in the pediatric patient. Yale J Biol Med. 1984;57:135-47.

10. Rayhorn N, Thrall C, Silber G. A review of the causes of lower gastrointestinal tract bleeding in children. Gastroenterol Nurs. 2001;24:77-82

11. Leung AK, Wong AL. Lower gastrointestinal bleeding in children. Pediatr Emerg Care. 2002; 18: 319-23.

12. Wajeehuddin AR. Per rectal bleeding in children. J Surg Pakistan. 2008;13: 47-50.

13. El-Khayat HA, El-Hodhod MA, Abd El-Basset FZ, Tomoum HY, El-Safory HA, Hamdy AM. Rectal bleeding in Egyptian children. Ann Trop Pediatr. 2006;26: 337-44.

14. Yu B, Jun P, Jun G, Duo WZ, Zhao-SL. Epidemiology of lower gastrointestinal bleeding in China: Single-center series and systematic analysis of Chinese literature with 53951 patients. J Gastroenterology and Hepatology. 2011; 26: 678-82.

15. Arain Z, Rossi TM. Gastrointestinal bleeding in children: an overview of conditions requiring non-operative management. Semin Pediatr Surg. 1999;8: 172-80.
16. Kumar AR, Jaypi VK, Sharma BE, Chawla YK, Baijal SS, Sarin SK et al. Experience of 330 Indian child with colorectal polyps. Am J Gastroenterol. 2009; 66:923-30.

17. Andrew JP, Philips TM, Black. Management of colonic polyps. Ind J Gasroenterol 2008; 78: 351-57.

18. Taylors DS, Cotton GT, Richard VD. Management of juvenile colorectal polyps. Surg Gastroenterol. 2009; 66: 923-30.

19. Chen US, Chau RH, Liu VE, Huang ES, Sung JJ, Chau $\mathrm{AE}$ et al. Role of sigmoidoscopy in children in with persistent lower gastrointestinal bleeding. J Paed Child Health 2010. 47:658-62.

20. Lovel GP. Malignant changes injuvenile colorectal polyps. Chin J PaedSurg. 2009;45:127-32.

21. Morrison CI, Robbin MJ George RB, Edward SJ, Seriver $\mathrm{CR}$, Jones NC et al. A prospective study of the changing pattern of juvenile colorectal polyps. Scand J Gastroenterol. 2010; 43:54-60.

22. Luky NM, Ford KS, Jones PG, Holmes GL, Laroia N, Morron $\mathbf{J}$ et al. Lower gastrointestinal bleeding: protocol for management in paediatricage .Int $\mathrm{J}$ Gastroenterol. 2010; 27:51-56.

23. Gupta CV, Steele WN, Gorden AS, Valente A, Kluth D, Spitz L et al. Revision of juvenile colorectal polyps in North America Chidren. Eypt J Gastroenterol. 2009; 28:62-67.

24. Bai Y, Peng J, Gao J, Zou DW, Li ZS. Epidemiology of lower gastrointestinal bleeding in China: single-center series and systematic analysis of Chinese literature with 53,951 patients. J Gastroenterol Hepatol. 2011;26678-82

25. Bradley TJ, Franklin FV, Sing BD. Colonoscopy and diagnostic radiology in management of colorectal polyps. Can J Paed Surg. 2009; 36 :503-9.

26. Morrison CI, Robbin MJ, George RB. A prospective study of the changing pattern of juvenile colorectal polyps. Scand J Gastroenterol. 2010; 43:54-60.

27. Ojuawo A, St Louis D, Lindley KJ, Milla PJ. Noninfective colitis in infancy: evidence in favour of minor immunodeficiency in its pathogenesis. Arch Dis Child. 1997;76:345-48.

28. Poddar U, Thapa BR, Vaiphei K, Singh K. Colonic polyps experience of 236 Indian children. Am J Gastroenterol. 1998; 93: 619-22 